Azizah, E. • A. Setyawan · M. Kadapi • Y. Yuwariah • D. Ruswandi

\title{
Identifikasi morfologi dan agronomi jagung hibrida Unpad pada tumpangsari dengan padi hitam di dataran tinggi Arjasari Jawa Barat
}

\section{Morphology and agronomical identification of Unpad maize hybrids under intercropping with black rice in Arjasari up land, West Java}

Diterima : 15 November 2016/Disetujui : 15 Desember 2016 / Dipublikasikan : 30 Desember 2016

CDepartment of Crop Science, Padjadjaran University

\begin{abstract}
Maize production in Indonesian has not been able to cover the high demand for national maize. Black rice also generally experience the same conditions. Efforts to increase maize production can be increased through the use of hybrid maize. However, the use of hybrid varieties will bring environmental problems due to over application of synthetic fertilizers. Environmental modifications actively on the cultivation of hybrid maize and black rice can be done by intercropping. This is one solution that is environmentally healty because it enriches organic and anorganic materials through the selection of a second crop selectively, prevent crop failure, food diversification and intake different nutrition. The purpose of this study was to get the best unpad hybrid maize varieties that have the performance of morphological and agronomic crops such as black rice in the up lands. Field trial using a randomized block design with 18 treatments (unpad hybrid maize) and 1 varieties commercially as a check. To selected the best maize hybrid analysis followed by Least Significant Increase (LSI) test. The results showed that in the condition of intercropping with a black rice, leaf length character with a maize hybrid selected JH6, JH17, JH12, and the character of dry seed grain weight, with a hybrid elected JH17, JH12, JH8, JH1 and JH14, were increased then check. The leaves and dry seed grain weight is an important character associated with a high yield in maize hybrids.
\end{abstract}

\footnotetext{
Dikomunikasikan oleh Anne Nuraini

Azizah, E. ${ }^{1} \cdot$ A Setyawan $^{2} \cdot$ M. Kadapi ${ }^{3} \cdot$ Y. Yuwariah $\cdot$ D. Ruswandi ${ }^{3}$

1Staf Pengajar Univ. Singaperbangsa Karawang (Unsika), Jln. HS Ronggowaluyo Telukjambe Karawang, Jawa Barat

${ }^{2}$ Mahasiswa Program Sarjana Univ. Singaperbangsa Karawang

${ }^{3}$ Staf Pengajar Universitas Padjadjaran (Unpad)

Korespondensi: eliaqusyairi@gmail.com
}

However, this condition giving the same results at ear height and chlorophyll content. To obtain hybrid maize unpad more stable and adaptive needs to do further testing on the season and a different altitude.

Keywords: Morphology-Agronomy $\cdot$ Hybrid maize $\cdot$ Black rice $\cdot$ Intercropping

Sari Produksi jagung di Indonesia belum mampu menutupi tingginya permintaan jagung nasional. Padi hitam pun secara umum mengalami kondisi yang sama. Upaya peningkatan produksi jagung dapat ditingkatkan melalui penggunaan jagung hibrida. Namun, penggunaan varietas hibrida akan mendatangkan permasalahan lingkungan karena over aplikasi pupuk sintetis. Modifikasi lingkungan secara aktif pada budidaya hibrida jagung dan padi hitam dapat dilakukan dengan cara tumpangsari. Hal ini merupakan salah satu solusi yang ramah lingkungan karena memperkaya bahan organik dan anorganik melalui pemilihan tanaman kedua secara selektif, mencegah gagal panen, diversifikasi pangan dan asupan nutrisi yang berbeda. Tujuan dari penelitian ini adalah mendapatkan varietas jagung hibrida unpad yang memiliki penampilan morfologi dan agronomi terbaik dalam tumpangsari dengan padi hitam di dataran tinggi. Percobaan lapangan menggunakan rancangan acak kelompok dengan 18 perlakuan jagung hibrida unpad dan 1 varietas komersil sebagai cek. Untuk mendapatkan Jagung hibrida terpilih analisis dilanjutkan dengan uji Least Significant Increase (LSI). Hasil penelitian memperlihatkan bahwa dalam kondisi tumpangsari dengan padi hitam, karakter panjang daun dengan hibrida terpilih JH6, JH17, JH12, dan karakter bobot biji pipilan kering, dengan hibrida terpilih JH17, JH12, JH8, 
JH1 dan JH14, memberikan hasil tertinggi dibandingkan cek. Panjang daun dan bobot biji pipilan kering merupakan karakter penting terkait dengan hasil yang tinggi pada jagung hibrida. Namun, memberikan hasil yang sama pada tinggi tongkol dan kandungan klorofil. Untuk mendapatkan jagung hibrida unpad yang lebih stabil dan adaptif perlu dilakukan pengujian lebih lanjut pada musim dan ketinggian tempat yang berbeda.

Kata kunci : Morfologi-Agronomi • Hibrida • Jagung · Padi hitam · Tumpangsari

\section{Pendahuluan}

Jagung sebagai bahan pangan utama setelah padi menjadi salah satu komoditas yang terus mengalami peningkatan permintaan seiring dengan berkembangnya industri pengolahan jagung dan pakan ternak. Menurut BPS (2015), produksi nasional jagung mencapai 19,61 juta ton sementara kebutuhan dalam negeri mencapai 25 juta ton. Oleh karena itu, dibutuhkan upaya peningkatan produksi jagung yang salah satunya adalah penggunaan varietas hibrida. Varietas jagung hibrida menjadi salah satu andalan dalam peningkatan produksi Jagung karena memiliki daya hasil yang tinggi melalui efek heterosisnya (Fehr, 1987).

Peningkatan produktivitas melalui jagung hibrida dapat mencapai 10-13 t/ha, berbeda jauh dari benih non hibrida yang hanya $<3$ t/ha (Balitsereal, 2010). Varietas jagung hibrida pada aplikasinya memiliki dampak buruk terhadap lingkungan. Tantangan yang dihadapi dengan hasil perbaikan varietas yang dibuat akan datang pada biaya lingkungan yang tinggi karena over aplikasi pupuk sintetis yang tidak bisa dicegah (Robertson dan Vitousek, 2009 dalam Yan, et al., 2011). Oleh karena itu, dibutuhkan suatu teknik budidaya jagung hibrida yang tetap memerhatikan kesehatan lingkungan dengan hasil yang tetap tinggi.

Upaya untuk menanggulangi permasalahan lingkungan akibat pupuk sintetis ataupun penggunaan lahan yang sub optimal dapat diatasi melalui modifikasi lingkungan tumbuh, salah satunya adalah tumpangsari. Tumpangsari diyakini dapat memberikan solusi karena pada sistim tanam ini lingkungan dapat dimodifikasi melalui pemilihan tanaman kedua secara selektif (Ruswandi, et al., 2016). Manfaat lain pada tumpangsari melalui modifikasi kondisi lingkungan secara aktif akan memberikan hasil optimal karena dapat mengurangi resiko gagal panen, diversifikasi pangan, pengayaan unsur organik dan anorganik, mengurangi serangan hama penyakit serta mencegah erosi (Vandermeer, 1989; Kumar et al, 2012; Ruswandi et al., 2016).

Pemilihan tanaman kedua sebagai tanaman pendamping bagi Jagung harus memerhatikan aspek ekologi (Kleinheiz, 1998), fisiologis dan ekonomis (Bantie, 2015). Jagung sebagai tanaman C4 membutuhkan intensitas cahaya penuh, sementara padi sebagai tanaman C3 menghendaki sebaliknya, dengan demikian melalui modifikasi lingkungan secara aktif dengan mempertimbangkan aspek fisiologis tanaman maka tumpangsari jagung dan padi akan menghasilkan interaksi yang positif. Hal ini didukung pula secara ekonomis, padi hitam merupakan salah satu pangan fungsional yang memiliki khasiat antioksidan, khasiat tersebut menjadikan permintaan padi hitam terus meningkat. Oleh karena itu, pemilihan padi hitam sebagai tanaman kedua pada sistim tumpangsari dengan jagung dapat meningkatkan produksi kedua komoditas tersebut.

Sistim tumpangsari pada aplikasinya adalah menanam lebih dari satu tanaman pada lahan dan periode tanam yang sama (Yuwariah, 2011). Akibatnya, pada kondisi ini akan terjadi interaksi antara tanaman utama dan tanaman kedua. Interaksi yang terjadi dapat bersifat positif atau saling mendukung maupun negatif. Pada tumpangsari jagung/legume, menunjukkan bahwa jagung memiliki hasil yang lebih tinggi pada bobot biji per plot dan bobot tongkol dengan kelobot hijau (Silva, et al., 2012). Pada penelitian lain dimana jagung manis unpad di tumpangsarikan dengan cabai memberikan produktivitas hasil tertinggi, ratio kompetisi menengah dan indek toleransi rendah saat cabai ditumpangsarikan dengan jagung pada pola 2:1 (Ruswandi et al., 2016). Hasil akhir yang diharapkan pada tumpangsari sebenarnya adalah optimum bagi kedua komoditas yang diusahakan. Oleh karena itu, menjadi hal yang penting untuk mengidentifikasi awal karakter agronomi Jagung hibrida unpad yang memberikan hasil yang lebih tinggi dibandingkan tanaman cek pada sistim tumpangsari dengan padi hitam.

Identifikasi karakter agronomi menjadi acuan awal dalam memilih hibrida dengan hasil 
yang tinggi pada tumpangsari. Karakter agronomi erat kaitannya dengan hasil dan komponen hasil yang menjadi tujuan utama meningkatkan produksi jagung. Namun demikian, karakter ini umumnya sangat dipengaruhi oleh lingkungan (Phoelman \& Sleeper, 1995). Arjasari merupakan representasi lingkungan untuk dataran tinggi di Jawa Barat. Ketinggian tempat berpengaruh terhadap suhu udara, kelembaban udara dan intensitas cahaya. Semakin tinggi suatu tempat semakin rendah suhu udara, kelembaban semakin tinggi dan intensitas cahaya semakin rendah. Keadaan tersebut akan berpengaruh terhadap proses fisiologi tanaman terutama fotosinesis dan respirasi (Taiz \& Zeiger, 2006). Oleh karena itu, identifikasi karakter agronomi jagung hibrida dalam lingkungan tumpangsari dengan padi hitam di dataran tinggi penting untuk dilakukan.

\section{Bahan dan Metode}

Percobaan dilakukan selama bulan Maret 2016 sampai Juli 2016 di Kebun Percobaan SPLPP Unpad Unit Arjasari, Jawa Barat, dengan ketinggian tempat $\pm 700 \mathrm{~m}$ dpl dengan titik ordinat $7^{\circ} 00^{\prime} 31.3^{\prime \prime} \mathrm{LS} 107^{\circ} 32^{\prime} 47^{\prime \prime} \mathrm{BT}$ (dokumenasi pribadi). Suhu rata-rata harian pada saat percobaan $\pm 18-31^{\circ} \mathrm{C}$ dan kelembaban $\pm 80 \%$. Bahan yang digunakan yaitu 18 jagung hibrida unpad dan 1 hibrida komersial yaitu varietas Pertiwi sebagai pembanding (Tabel 1). Jagung hibrida unpad menjadi perlakuan yang kemudian diulang sebanyak 2 ulangan. Sementara itu, padi hitam yang digunakan merupakan varietas lokal asal Subang.

Sistim tumpangsari yang diaplikasikan berupa tumpangsari barisan (row intercropping), yaitu satu baris jagung hibrida dan satu baris padi. Dengan demikian luas petakan yang digunakan adalah $4,5 \mathrm{~m}^{2}$ dengan jarak antar baris $75 \mathrm{~cm}$ dan dalam baris $20 \mathrm{~cm}$.

Data hasil pengamatan di lapangan dianalisis berdasarkan analisis varian untuk rancangan acak kelompok (RAK) (Gomez \& Gomez, 1995). Uji lanjut untuk mendapatkan hibrida terbaik di analisis dengan Uji Least Significant Increase (Petersen, 1998). Adapun karakter yang di amati meliputi tinggi letak tongkol $(\mathrm{cm})$, kandungan klorofil $(\mathrm{CCI})$, panjang daun $(\mathrm{cm})$, dan bobot biji 3 sampel pipilan kering $(\mathrm{kg})$.
Tabel 1. Daftar nama hibrida Jagung Unpad yang digunakan

\begin{tabular}{|c|c|c|}
\hline No & Kode Genotipe & Hibrida \\
\hline 1 & $\mathrm{JH1}$ & DR $10 \times$ MDR 9.1.3 \\
\hline 2 & JH2 & DR 10 x DR 18 \\
\hline 3 & $\mathrm{JH} 3$ & DR $10 \times$ DR 8 \\
\hline 4 & $\mathrm{JH} 4$ & DR 10 x G 20133077 \\
\hline 5 & JH5 & MDR 9.1.3 x MDR 1.1.3 \\
\hline 6 & JH6 & MDR 9.1.3 x G 203.1 \\
\hline 7 & JH7 & MDR 7.4.1 x DR 18 \\
\hline 8 & JH8 & MDR 7.4.1 x MDR 18.8.1 \\
\hline 9 & JH9 & MDR 7.4.1 x MDR 1.1.3 \\
\hline 10 & JH10 & MDR 14.2.2 x G 20133077 \\
\hline 11 & JH11 & DR $8 \times$ MDR 3.1 .4 \\
\hline 12 & JH12 & DR $8 \times$ G 673 \\
\hline 13 & JH13 & DR 8 x G 20133077 \\
\hline 14 & JH14 & DR $8 \times$ MDR 18.8 .1 \\
\hline 15 & JH15 & DR 8 x MDR 1.1 .3 \\
\hline 16 & JH16 & G 673 x G 20133077 \\
\hline 17 & JH17 & G 20133077 x G 203.1 \\
\hline 18 & JH18 & MDR 18.8.1 x MDR 7.1.9 \\
\hline 19 & JH19 & $\begin{array}{l}\text { Hibrida Pertiwi } \\
\text { (Cek/Pembanding) }\end{array}$ \\
\hline
\end{tabular}

\section{Hasil dan Pembahasan}

Kondisi agroekosistem pada sistim tumpangsari jagung hibrida unpad dengan padi hitam di dataran tinggi secara nyata telah memberikan pengaruh pada panjang daun dan bobot biji 3 sampel, namun menunjukkan penampilan dan hasil yang sama pada karakter tinggi letak tongkol dan kandungan klorofil (Tabel 2).

Tabel 2. Analisis Varian Karakter Morfo-Agro Hibrida Jagung pada Tumpangsari dengan Padi Hitam

\begin{tabular}{lrrrr}
\hline \hline $\begin{array}{l}\text { Sumber } \\
\text { Varian }\end{array}$ & $\begin{array}{c}\text { Tinggi } \\
\text { letak } \\
\text { Tongkol }\end{array}$ & $\begin{array}{c}\text { Kandu- } \\
\text { ngan } \\
\text { Klorofil }\end{array}$ & $\begin{array}{c}\text { Panjang } \\
\text { Daun }\end{array}$ & $\begin{array}{c}\text { Bobot } \\
\text { Biji 3 } \\
\text { sampel }\end{array}$ \\
\hline Ulangan & 986,34 & 253,36 & 40,33 & 0,0048 \\
Perlakuan & 123,15 & 19,42 & 36,37 & 0,0150 \\
Galat & 785,81 & 29,41 & 9,84 & 0,0034 \\
F hit & $0,16^{\text {ns }}$ & $0,66^{\text {ns }}$ & $3,70^{*}$ & $4,4118^{*}$ \\
CV $(\%)$ & 9,20 & 14,50 & 3,20 & 11,70 \\
\hline \hline
\end{tabular}

Jagung dan Padi hitam merupakan tanaman yang memiliki famili yang sama (Graminae). Vandermeer (1998) menjelaskan bahwa pemilihan komoditas tanaman pada sistim tanam campuran harus memperhatikan prinsip eksklusi dalam kompetisi. Prinsip ini mengatur untuk menghindari pemilihan 
komoditas tanaman yang satu famili karena dapat berakibat pada kompetisi unsur hara yang sama. Namun, Indonesia sebagai negara yang masyarakatnya memiliki budaya mengonsumsi padi sebagai makanan pokok, selain itu didukung oleh luas kepemilikan lahan yang sempit ( $\pm 0,25$ ha) dan pengolahan lahan yang sederhana (Ruwandi et. al., 2016) membutuhkan hibrida jagung yang dapat tumbuh optimal dalam kondisi tumpangsari dengan padi hitam di dataran tinggi. Dengan harapan, petani dapat menghindari gagal panen, diversifikasi pangan, dan asupan nutrisi yang berbeda (Yuwariah, 2011).

Komponen morfologi menjadi karakter yang penting diamati untuk mengetahui pengaruhnya terhadap proses pertumbuhan dalam kondisi tumpangsari. Daun salah satu komponen morfologi yang utama bagi tanaman. Semakin panjang daun maka semakin tinggi potensi tanaman tersebut untuk fotosintesis. Pada agroekosistem dataran tinggi dimana intensias cahaya matahari tidak setinggi dataran rendah akan membutuhkan varietas hibrida jagung berdaun panjang, hal ini berkaitan dengan luas penampang daun dalam menyerap sinar matahari yang pada akhirnya berujung pada aktivitas fotosintesis.

Hasil uji lanjut dengan LSI mendapatkan 3 jagung hibrida unpad yang memiliki panjang daun lebih tinggi dari tanaman cek. Pada Tabel 3, dapat dijelaskan bahwa hibrida JH 6 merupakan hibrida dengan panjang daun yang paling tinggi dibandingkan tanaman cek dan hibrida yang lainnya, kemudian disusul dengan JH 17 dan JH 12.

Jagung hibrida sebagai tanaman C4 memberikan interaksi yang positif pada tumpangsari dengan padi hitam (padi gogo) sebagai tanaman C3. Hal ini didasarkan bahwa variasi penggunaan varietas yang berbeda dapat menurunkan intensitas serangan hama dan penyakit (Akboola \& Fayemi, 1971; Bhatnagar \& Davies, 1981; dalam Kleinheiz, 1998; Ibeawuchi, 2007). Pada agroekosistem dataran tinggi (ketinggian $\pm 700 \mathrm{~m}$ dpl) yang memiliki intensitas cahaya sedikit lebih rendah namun kelembaban cukup tinggi, perubahan suhu dan kelembaban secara drastis dapat menyebabkan terjadinya serangan bulai pada jagung. Namun, pada kondisi tumpangsari diharapkan akan mengurangi serangan hama penyakit tersebut.

Efekivitas tanaman jagung hibrida dalam memanfaatkan luasnya penampang daun untuk berfotosintesis telah berpengaruh terhadap bobot biji pipilan kering pada 3 sampel tanaman (komponen agronomi). Hibrida-hibrida terpilih hasil analisis LSI memperlihatkan hasil yang hampir sama dengan hibrida-hibrida yang terpilih untuk karakter panjang daun, seperti dapat dilihat pada Tabel 4.

Karakter bobot biji pada 3 sampel tanaman tertinggi dimiliki oleh hibrida JH 17 yaitu hasil persilangan antara tetua G 20133077 X G 203 1, disusul oleh JH12, JH8, JH1 dan JH14. Karakter bobot biji 3 sampel merupakan cerminan komponen hasil secara individu. Sehingga, dapat disimpulkan bahwa panjang daun yang dimiliki oleh hibrida-hibrida jagung unpad memberikan hasil yang optimal pula pada bobot biji 3 sampel hibrida jagung unpad. Oleh karena itu, karakter-karakter ini diharapkan dapat menjadi acuan untuk memilih hibrida jagung unpad terbaik yang mampu tumbuh optimal pada sistim tumpangsari dengan padi hitam.

Tabel 3. Hibrida Jagung Unpad Terpilih Untuk Karakter Panjang Daun Pada Tumpangsari dengan Padi hitam

\begin{tabular}{cllcc}
\hline \hline Peringkat & \multicolumn{1}{c}{ Kode Entri } & \multicolumn{1}{c}{ Nama Hibrida } & Rata-rata (cm) & Nilai Increase \\
\hline $\mathbf{1}$ & JH 6 & M9DR 9.1.3 X G 203-1 & 107,3 & 6,28 \\
$\mathbf{2}$ & JH 17 & G 20133077 X G 203-1 & 103,8 & 2,78 \\
$\mathbf{3}$ & JH 12 & DR 8 X G 673 & 101,3 & 0,28 \\
\hline \hline
\end{tabular}

Tabel 4. Hibrida Jagung Unpad Terpilih Untuk Karakter Bobot Biji pipilan kering 3 Sampel pada Tumpangsari dengan Padi Hitam

\begin{tabular}{cllcr}
\hline \hline Peringkat & \multicolumn{1}{c}{ Kode Entri } & \multicolumn{1}{c}{ Nama Hibrida } & Rata-rata (kg) & Nilai Increase (kg) \\
\hline $\mathbf{1}$ & JH17 & G 20133077 X G 203-1 & 0,609 & 0,043 \\
$\mathbf{2}$ & JH12 & DR 8 X G 673 & 0,604 & 0,038 \\
$\mathbf{3}$ & JH8 & M9DR 7.4.1 X M7DR 18.8.1 & 0,596 & 0,030 \\
$\mathbf{4}$ & JH1 & DR 10 X M9DR 9.1.3 & 0,587 & 0,021 \\
$\mathbf{5}$ & JH14 & DR 8 X M7DR 18.8.1 & 0,571 & 0,004 \\
\hline \hline
\end{tabular}




\section{Kesimpulan dan Saran}

Kondisi agroekosistem pada jagung hibrida unpad yang tumpangsarikan dengan padi hitam di dataran tinggi memberikan pengaruh terhadap panjang daun dan bobot biji pipilan kering pada 3 sampel tanaman. Jagung hibrida unpad terpilih untuk panjang daun yang lebih tinggi dari cek adalah JH6, JH17 dan JH12, sementara itu untuk karakter bobot biji pipilan kering ( 3 sampel) peringkat pertama tertinggi dimiliki oleh JH17 disusul oleh JH12, JH8, JH1 dan JH14. Untuk mendapatkan hasil yang lebih stabil dan adaptif pada tumpangsari dengan padi hitam diperlukan pegujian lanjut pada ketinggian yang berbeda, agar didapatkan Jagung hibrida yang memiliki sabilitas dan adaptabilitas yang lebih luas.

\section{Ucapan Terima Kasih}

Terima kasih disampaikan kepada Kemenristek Dikti atas bantuan pendanaan penelitian melalui skema Hibah PUPT a.n Ir. Dedi Ruswandi, M.Sc., Ph.D.

\section{Daftar Pustaka}

Allard, R.W. 1960. Principles of plant Breeding. John Wiley and Sons, Inc. NewYork, London.

Bantie, B. Yayeh. 2015. Determination of effective spatial arrangement for intercropping of maize and potato using competition indices at South Wollo, Ethiopia. Vol. 3 (2), pp. 218225. ISSN: 2408-6886

Federer, W.T. 1989. Intercropping, Developing Countries, and Tropical Agriculture. Chapter 11. Springer : ISBN 9780387226477

Fehr, W.R. 1987. Principles of Cultivar Development. Macmillan Publ. Co., Inc. New York.

Gardner, Franklin P. 1985. Physiology of crop plants.Iowa State University Press. USA.
Gomez, K.A. \& A. A. Gomez. 1995. Prosedur Statistik untuk Penelitian Pertanian. Edisi Kedua. UI-Press.

Ibeawuchi, I . I. 2007. Intercropping - A Food Production Strategy for the Resource Poor farmers. Nature and Science, 5(1) : 46-59.

Kleinheinz, Volker. 1998. Intercropping With Legums in the tropics. AVRDC. Taiwan.

Kumar, R., J.Kaul, R.B. Dubey, A. Singode, G.K. Chikkappa, A. Manivannan and M.K. Debnath. 2012. Assesment of drought olerance in Maize (Zea mays) based on differen indices. Sabrao Journal Of Breeding and geneics 47 (3):291-298.

Petersen, R. G. 1985. Design and Analysis of Experiments. Marcel Dekker. New York.

Phoelman, J.M. and D.A. Sleeper. 1995. Breeding Field Crops. Iowa State University Press.

Ruswandi, D, J. Supriatna, N. Rostini, and E. Suryadi. 2016. Assessment of sweetcorn hybrids under sweetcorn/ chilli pepper intercropping in West Java, Indonesia. J. Agron., 15(3): 94-103. DOI: 10.392/ ja.2016.94.103.

Silva, P.S.L.2, Silva, P.I.B.3, Oliveira, V.R.4, Barros, G.L.5, and Monteiro, A.L. 2012. Corn Cultivar Intercropping With Arboreal Legumes For Weed Control. Planta Daninha, Viçosa-MG, v. 31, n. 3, p. 559-567.

Taiz, L and E. Zeiger. 2006. Plant Physiology, Fourth edition. Sinauer Associates, Inc. USA.

Vandermeer, J. 1989: The ecology of intercropping. Cambridge University Press. Cambridge.

Yan, J., M. Warburton, and J. Crouch. 2011. Association mapping for enhancing maize (Zea mays L.) genetic improvement. Crop Science Vol.51 : 433-449. DOI: 10.2135/ cropsci2010.04.0233

Yuwariah, Y. 2011. Dasar-Dasar Sistem Tanaman Ganda. Jurusan Budidaya Pertanian, Fakultas Pertanian UNPAD. Bandung.

Zhang, F. and Long Li. 2003. Using competitive and facilitative interactions in intercropping systems enhances crop productivity and nutrient-use efficiency. Journal of Plant and Soil 248: 305-312. 